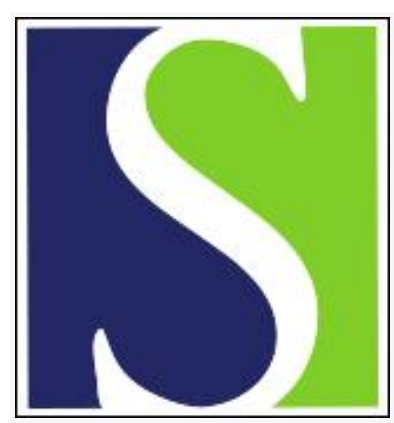

Scand J Work Environ Health 1996;22(1):1-3

https://doi.org/10.5271/sjweh.102

Issue date: Feb 1996

Buildings with moisture problems -- a new challenge to occupational health care

by Reijula $\mathrm{K}$

This article in PubMed: www.ncbi.nlm.nih.gov/pubmed/8685668

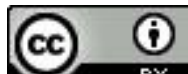




\section{Buildings with moisture problems - a new challenge to occupational health care}

The quality of indoor air has become extremely important to the western world since people today spend more than $90 \%$ of their time indoors in tightly sealed, poorly ventilated and overheated buildings. An increase in the incidence of allergic disorders has raised the question of a causal relationship between poor indoor air quality and such disorders. It is obvious that exposure to allergens in the indoor environment increases the risk of exposed individuals developing allergic rhinitis and asthma. Therefore, recent investigations have focused on the epidemiology of allergic diseases caused by animal-derived proteins (eg, cat and dog epithelium), which so far have been the most common allergens in indoor environments. But what happens if indoor air is contaminated with microorganisms (eg, bacteria and fungi) due to moisture problems and water leaks? Does the exposure to microorganisms also increase the risk of allergic diseases? Are there other disorders which can be associated with moisture problems in buildings? Are there other causative agents in damp housing which cause adverse health effects in persons occupying the buildings? Whatever the answers to these questions are, corrective construction should be launched in buildings with moisture problems before exposure to microorganisms develops into disease.

Moisture problems have been encountered with an increasing frequency both in family housing and in workplaces. According to recent investigations in the United States, Europe, and, especially, Scandinavia damp housing accounts for over $50 \%$ of all buildings. In Finland, one explanation for the unexpectedly high percentage of buildings with moisture damage is the fact that over $80 \%$ of all buildings were built after the Second World War and there is need for proper repair. Unfortunately, because of the lack of knowledge on indoor air problems associated with damp housing and because of the economic recession in recent years, construction activities have been postponed. In addition, not all buildings have been planned properly to survive rain, melting snow, and moisture, which soaks from surrounding ground directly into building materials. Flat roofs, which were especially popular in the 1970 s, are not as tight as they should be. Water leaks and moist building materials inevitably lead to the growth of molds and bacteria in these buildings. Due to the energy crisis two decades ago buildings were sealed tightly. If the ventilation systems of buildings do not function properly, relative humidity in the indoor environment increases, especially in tightly sealed buildings. This increase in humidity in turn leads to another form of moisture problem on the surfaces of building material. Black spots of mold on bathroom walls are common examples of poorly ventilated buildings. Moisture problems caused by increased relative humidity in addition to poor ventilation and tight sealing have to be distinguished from moisture problems which occur deeper in building materials and are caused by water leaks and passing moisture from the surrounding ground.

Most of the fungi and bacteria in moisture-problem buildings originates from the outdoor environment. The indoor environment and building materials with increased humidity are fruitful habitats for certain outdoor microorganisms. The microorganisms do not need special requirements to grow; water is practically all that they need. When the microorganisms begin to grow, they produce networks (hyphae) on the surface of building materials. At the time of poor conditions (draft and low temperature) molds develop spores (conidia) that can be sent to new frontiers to find other moist environments for their growth. Respiratory exposure of persons occupying water-damaged buildings occurs at the time of sporulation (emergence of spores from the hyphal fragments). 
The review by Husman in this issue of the Scandinavian Journal of Work, Environment \& Health contains a list of typical fungi and bacteria found in moisture-damaged buildings. What do we know about the microorganisms encountered in damp housing, and what are their health effects? Is there an increased risk of developing respiratory or dermal disorders after exposure to these fungi and bacteria? People have always been exposed to fungi and bacteria in their environment, even to the microorganisms which can be found in damp housing. If there is an increased incidence of illnesses due to damp housing confested with molds, something must have happened in the indoor environment. Either the quality or quantity of the microorganisms in indoor air has changed or the exposed persons have become more prone to develop "mold house diseases." At least the number of damp buildings with contamination from microorganisms seems to be higher than earlier.

Typical microorganisms encountered in damp housing were listed in a conference held in 1992 in Baarn, The Netherlands. Most of them are usually not found in "healthy buildings." Some of the microorganisms found in damp housing can cause allergic diseases either through an IgE-mast cellmediated (type I, "immediate") or cell-mediated (type IV, "delayed") allergy. For instance, exposure to Aspegillus fumigatus in buildings with moisture problems can induce the sensitization and production of $\lg \mathrm{E}$ (immunoglobulin $\mathrm{E}$ ) antibodies to $A$ fumigatus antigens (allergens). After the primary sensitization, the exposures that follow lead immediately (in $10-30 \mathrm{~min}$ ) to respiratory, dermal, or conjunctival symptoms, which appear as allergic rhinitis, asthma, conjunctivitis, or urticaria in exposed persons. Immediate allergy due to A fumigatus can be determined from measurements of specific IgE antibodies to the microorganisms in the patient's serum or by using the microbial antigen in skin prick tests. Hypersensitivity pneumonitis (extrinsic allergic alveolitis) is an example of a cell-mediated, delayed allergic reaction. In damp housing, exposure to microbial allergens may lead to allergic reaction in which symptoms appear as fever, cough, dyspnea, and fatigue $4-6 \mathrm{~h}$ after the exposure. Typical symptoms, abnormal findings in chest $X$ rays, and impaired lung function tests reveal the diagnosis of hypersensitivity pneumonitis due to microbial agents. Organic dust toxic syndrome, which can occur after exposure to microbic toxins, appears with fever, but it only seldom produces pathological findings in lung function studies or chest X-ray examinations. Therefore, the diagnosis of this disease is usually based on the history of environmental findings and the patient's symptoms.

According to the experience of my colleagues and I at the Finnish Institute of Occupational Health, only a minority of persons exposed to molds in moisture-problem buildings develops allergic diseases. Less than $10 \%$ of exposed workers in problem buildings were diagnosed with an IgE-mediated allergy (allergic rhinitis, asthma, conjunctivitis, or urticaria) and only $1-2 \%$ developed hypersensitivity pneumonitis. However, over $40 \%$ of the exposed persons in these buildings complained of respiratory or conjunctival symptoms associated with poor indoor air quality. It is obvious that insufficient ventilation partly explains the complaints. More likely the microorganisms themselves, fragments of fungi, or toxins cause the symptoms through direct contact or irritation.

Stachybotrys atra is one of the microorganisms found in indoor environments and especially in buildings with very damp conditions. $S$ atra is capable of producing highly potent toxins. Persons occupying damp housing confested with $S$ atra are at risk of developing stachybotryotoxicosis. Only a few descriptions exist of $S$ atra being detected in damp housing. Persons exposed in these buildings complained of headache, sore throat, flu symptoms, fatigue, dermatitis, and general malaise. Additional investigations are needed to ascertain the relationship between $S$ atra and diseases in exposed patients. Contact with fragments of fungi (ie, spores and hyphae) and metabolites from the microorganisms (eg, toxins) inevitably play a significant role in the pathogenesis of diseases associated with microbial exposure in damp housing.

Even more important is the fact that $S$ atra is able to produce metabolites that are immunosuppressive, such as cyclosporins, stachybotrylactones, and stachybotrylactams. An increased incidence of 
respiratory infections (eg, sinusitis and acute bronchitis) has recently been documented for occupants of damp housing. $S$ atra itself does not cause the infections, but it is able to decrease the defense mechanisms of the protective barrier in exposed persons so that viruses and bacteria are able to cause respiratory disorders

If the number of moisture-damaged buildings is as high as reported, national activities will be necessary in several countries to avoid the health consequences of exposure to molds in damp housing. National surveys of both public and private buildings should be carried out as soon as possible to evaluate the magnitude of moisture problems. By appropriating funds for construction activities, governments should encourage people to renovate buildings to eliminate the most severe problems.

What should be done when a water-damage problem with molds has been detected either in a workplace or at home? If accidental water-damage has occurred, it has to be repaired immediately. If the signs of water-damage are visible, the primary cause of the moisture problem should be determined. Only by eliminating the source can the problems with molds be avoided. People often paint spots caused by molds in order to hide the problem. Unfortunately, this maneuver makes the situation even worse, and the problem reappears in an even larger magnitude. Odors of molds are one of the first signs to warn occupants of the risk. Microbiological examinations of indoor air samples and specimens collected from surfaces and building materials can reveal the species of fungi existing in damp housing. If symptoms associated with poor indoor air quality have been reported by the residents, health care personnel should be involved. If moisture problems occur in a workplace, occupational health professionals should evaluate the magnitude of the problem (eg, by administering questionnaire surveys to people who work in the problem buildings). Clinical examinations have to be performed as a method to screen for symptomatic persons with diseases. Additional investigations accompanied by measurements of specific antibodies against microorganisms, lung function studies, provocation tests, and chest $X$ rays should be performed in special clinics (eg, in departments of occupational medicine) after the clinical screening. In private buildings municipal inspectors or private consultants should evaluate of the damp house problem with valid methods for estimating the severity of the moisture problem. Microbiological investigations should only be performed by professional laboratories with the needed expertise. Primary clinical examinations should be performed by municipal health care centers, which should have at least one physician familiar with the health problems of damp houses. After the screening, the patients should be sent to special clinics if necessary. Additional scientific studies are needed to develop proper methods for examining exposed patients.

In Finland there are approximately 1.2 million buildings. If over $50 \%$ of the buildings are waterdamaged to a certain extent and if over 100000 buildings have been infested with molds, over 400000 of the 5.1 million Finns have been exposed to fungi in indoor environments. It is extremely important to determine the actual number of moisture-problem buildings, correct the condition of the ones in most need of repair, develop methods with which to diagnose "mold house diseases," and avoid unnecessary exposure in the future. In Finland, the Ministry of Social Affairs and Health has launched activities to resolve existing questions on the health effects associated with damp housing, and the Ministry of Labour has appropriated funds for correcting poor conditions in public buildings. The first step has been taken, but much more has yet to be done.

Kari Reijula, MD

Finnish Institute of Occupational Health

Arinatie $3 \mathrm{~A}$

FIN-00370 Helsinki, Finland 